Nat. Hazards Earth Syst. Sci., 18, 479-489, 2018

https://doi.org/10.5194/nhess-18-479-2018

(C) Author(s) 2018. This work is distributed under the Creative Commons Attribution 3.0 License.

\title{
Comparison of lightning activity in the two most active areas of the Congo Basin
}

\author{
Jean K. Kigotsi ${ }^{1,2}$, Serge Soula ${ }^{1}$, and Jean-François Georgis ${ }^{1}$ \\ ${ }^{1}$ Laboratoire d'Aérologie, Université de Toulouse, CNRS, Toulouse, France \\ ${ }^{2}$ Département de Physique, Faculté des Sciences, Université de Kinshasa, Kinshasa, Democratic Republic of Congo \\ Correspondence: Jean K. Kigotsi (jeankigotsi@gmail.com) and Serge Soula (serge.soula@aero.obs-mip.fr)
}

Received: 16 March 2017 - Discussion started: 12 June 2017

Revised: 27 October 2017 - Accepted: 14 December 2017 - Published: 13 February 2018

\begin{abstract}
A comparison of the lightning activity in the two most active areas (Area_max for the main maximum and Area_sec for the secondary maximum) of the Congo Basin is made with data obtained by the World Wide Lightning Location Network (WWLLN) during 2012 and 2013. Both areas of same size $\left(5^{\circ} \times 5^{\circ}\right)$ exhibit flash counts in a ratio of about 1.32 for both years and very different distributions of the flash rate density (FRD) with maximums in a ratio of 1.94 and 2.59 for 2012 and 2013, respectively. The FRD is much more widely distributed in Area_sec, which means the whole area contributes more or less equal to the lightning activity. The diurnal cycle is much more pronounced in Area_max than in Area_sec with a ratio between the maximum and the minimum of 15.4 and 4.7, respectively. However, the minimum and maximum of the hourly flash rates are observed roughly at the same time in both areas, between 07:00 and 09:00 UTC and between 16:00 and 17:00 UTC, respectively. In Area_sec the proportion of days with low lightning rate ( $0-1000$ flashes per day) is much larger $(\sim 45 \%$ in 2013$)$ compared to Area_max ( $23 \%$ in 2013). In Area_max the proportion of days with moderate lightning rate (1001-6000 flashes per day) is larger ( $\sim 68.5 \%$ in 2013$)$ compared to Area_sec $(\sim 46 \%$ in 2013$)$. The very intense convective events are slightly more numerous in Area_sec. In summary, the thunderstorm activity in Area_sec is more variable at different scales of time (annually and daily), in intensity and in location. Area_max combines two favourable effects for thunderstorm development, the convergence associated with the African easterly jet of the Southern Hemisphere (AEJS) and a geographic effect due to the orography and the presence of a lake. The location of the strong convection in Area_sec is modulated by the distance of westward propaga-
\end{abstract}

tion/regeneration of mesoscale convective systems (MCSs) in relation to the phase of Kelvin waves.

\section{Introduction}

According to several studies about the lightning climatology around the Earth, the Congo Basin is considered as the most active region with either a large maximum or two distinct ones (Christian et al., 2003; Williams and Sátori, 2004; Albrecht et al., 2011, 2016; Cecil et al., 2014; Soula et al., 2016). Actually, the features of the maximum area depend on the spatial resolution considered in the calculation of the flash rate density (FRD) and the scale resolution in the graphic representation. Albrecht et al. (2016) performed a very detailed analysis of FRD thanks to Lightning Imaging Sensor (LIS) data around the Earth by using several spatial resolutions. They showed the features of the maxima FRD strongly depend on the spatial resolution and on the duration of the period considered for the study. Thus, the location and the value of the first- and second-ranked maxima FRD stabilize when the period is longer. With the better resolution $\left(0.1^{\circ}\right)$ used in Albrecht et al. (2016), the second-ranked hotspot is always located around $\left[28^{\circ} \mathrm{E}, 2^{\circ} \mathrm{S}\right]$ from 5 years of data. Furthermore, they showed most of the first 10 lightning hotspots over the entire African continent, including the strongest ones, are located in Democratic Republic of Congo (DRC). By considering the maps of FRD in Albrecht et al. (2016), the existence of two regions of maximum activity in DRC is displayed, but the non-linear scale does not allow a quantitative comparison of the maximum values. 
Cecil et al. (2014) provided two maps of lightning flash density from the Lightning Imaging Sensor (LIS) and Optical Transient Detector (OTD) data with different resolution, 0.5 and $2.5^{\circ}$, and a non-linear scale. With a $0.5^{\circ}$ resolution, two maxima are distinguished in the region of Congo Basin and only one with a $2.5^{\circ}$ resolution. Two separated maxima are also visible in the study by Christian et al. (2003) with a resolution of $0.5^{\circ}$ and a non-linear scale of density. However, in the latter study, neither maximum remains throughout the year in considering the lightning activity with 3-month seasons. Recently, Soula et al. (2016) showed a very pronounced maximum in the annual and seasonal lightning flash density in the eastern Democratic Republic of Congo (DRC) from World Wide Lightning Location Network (WWLLN) data with a $0.1^{\circ}$ resolution and a linear scale. In this study, a secondary maximum was also highlighted west of the main maximum, especially during the first part of the 9-year period of study. This secondary maximum was less pronounced and scattered over a large area. In this study the region of maximum activity could be analysed in detail because the linear scale for flash density was better adapted for large values compared to previous studies.

The results of Soula et al. (2016) provided the following characteristics. The main maximum in lightning flash density is observed every year in one small region of the DRC, at about $28^{\circ} \mathrm{E}$ and between 1 and $2^{\circ} \mathrm{S}$. This maximum is embedded within a region of large values of lightning flash density, strongly contrasting with the whole study area. The geographical extent of this region is approximately $300 \mathrm{~km}$ north-south and $200 \mathrm{~km}$ east-west. It is located in the area where many authors identified the maximum of planetary lightning activity: Christian et al. (2003), who falsely attributed it to Rwanda; Cecil et al. (2014); and Albrecht et al. (2011). The high spatial resolution and the linear scale used in Soula et al. (2016) allowed a better localization and specification of its shape and amplitude characteristics. In addition, the maximum number of days with thunderstorms has been found in the same area (189 days of storms in 2013) as the average number of flashes per day of storms (approximately 8 flashes per day). Another area of large flash density considered as a secondary maximum was pointed out in Soula et al. (2016). This area was broader but less contrasting from year to year during the period of the study. It extends roughly from the centre of DRC to Congo to the west and to Angola to the south.

The goal of this study is to compare the characteristics of lightning activity in the two areas of maximum activity. The second section describes the data and the methodology used, the third section presents the results from several comparisons, and the fourth section is devoted to a discussion.

\section{Data and methodology}

By following the study by Soula et al. (2016), we define two areas of the same extent: one for the main maximum considered as "Area_max" and the other for the secondary maximum considered as "Area_sec". They are identified by latitude and longitude values in the following intervals:

\section{$\left[25^{\circ} \mathrm{E}, 30^{\circ} \mathrm{E}\right]$ and $\left[4^{\circ} \mathrm{S}, 1^{\circ} \mathrm{N}\right]$ for Area_max \\ $\left[18^{\circ} \mathrm{E}, 23^{\circ} \mathrm{E}\right]$ and $\left[4^{\circ} \mathrm{S}, 1^{\circ} \mathrm{N}\right]$ for Area_sec.}

We use data from the WWLLN for the present study. The WWLLN (www.wwlln.net/) is a global lightning detection network around the Earth. The electromagnetic radiation emitted by lightning strokes (from cloud-to-ground and intracloud flashes) at very low frequency (VLF) and called sferics are detected by the sensors of the WWLLN (Abarca et al., 2011). These strokes are then localized by using the time of group arrival technique (TOGA) (Dowden et al., 2002). The stations can be separated by thousands of kilometres because VLF frequencies can propagate within the Earth-ionosphere wave guide with very little attenuation. Since its implementation in March 2003, the WWLLN has been improved in terms of number of stations and development of the processing algorithm (Rodger et al., 2008). In order to give an idea of the growth of the number of WWLLN stations spread on the planet, they numbered 11 in 2003, then 23 in 2005, 30 in 2007, and 67 in 2013, according to the report made by Rodger et al. (2014). Thus, the changes in the network during this 10-year period (2003-2013) can explain the continuous increase in the detection efficiency (DE) observed by Soula et al. (2016) in the total domain of the study. According to Abarca et al. (2011), DE for CG flashes is about twice that for IC flashes.

We analyse the DE evolution during this period for each area. For this purpose and in the same way as Soula et al. (2016) for the whole Congo Basin area, Fig. 1 displays the annual numbers of lightning flashes detected by WWLLN and LIS in Area_max and Area_sec during the period 20052013. In the same graph, the values of the WWLLN DE relative to the LIS data, are reported for each area. DE is calculated by following the methodology developed by Soula et al. (2016), i.e. by applying the correction coefficient for the estimation of the number of the whole lightning flashes LIS could detect with a continuous survey. First, the number of flashes detected by LIS in each area does not vary much during the period, it is always larger in Area_max, its minimum is observed for 2007 in each area and more pronounced for Area_sec, and the maximum is observed for 2005 in each area too. Thus, no increase tendency is observed in each area. Secondly, the number of flashes detected by WWLLN in each area increases after 2008, especially during the last 2 years, 2012 and 2013. As a consequence, DE is significantly larger for 2012 and 2013, and reaches 4.96 and $7.50 \%$ in Area_max, respectively, and 4.24 and $6.11 \%$ in Area_sec. 


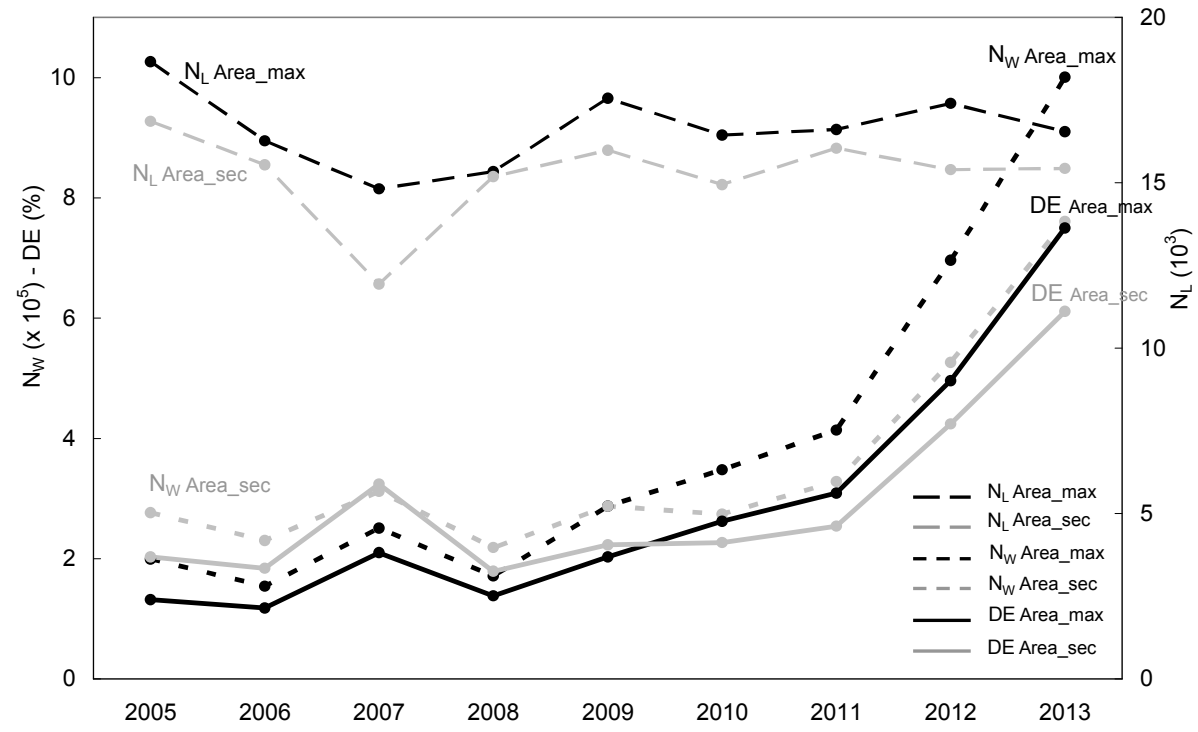

Figure 1. Annual number of flashes detected by the WWLLN $\left(N_{\mathrm{W}}\right)$ and that detected by LIS $\left(N_{\mathrm{L}}\right)$ for each area, and estimated detection efficiency (DE) for WWLLN data relative to LIS data, according to the methodology developed in Soula et al. (2016).

This increase in DE is completely independent of the number of flashes detected by LIS that is relatively stable during the last years, which means it is totally related to the WWLLN performance. According to the DE values, we select the last 2 years of the period (2012 and 2013) for a comparison of the characteristics of the lightning activity in Area_max and Area_sec.

\section{Results}

\subsection{Spatial distribution of the lightning activity}

Figure $2 \mathrm{a}-\mathrm{b}$ show the annual FRD, in flashes (fl) $\mathrm{km}^{-2} \mathrm{yr}^{-1}$, calculated with a resolution of $0.05^{\circ}$ from WWLLN data in the large domain of the Congo Basin for 2012 and 2013, respectively. Figure $2 \mathrm{c}-\mathrm{d}$ show the number of days of the year with lightning activity in the same domain with the same resolution for 2012 and 2013, respectively. The white frames indicate the two areas with strong activity (left Area_sec and right Area_max). Table 1 displays the flash count, the maximum FRD for both areas and for each year. Both areas of same size $\left(5^{\circ} \times 5^{\circ}\right)$ exhibit total flash counts in a ratio of about 1.32 for both years, which indicates a stable situation from one year to the next. However, the ratio of the maximum FRD is very different from one year to the next, since it is 1.94 and 2.59 for 2012 and 2013, respectively. This difference can be easily understood since the maximum value is very localized and can change substantially from one year to the next, and furthermore the spatial density resolution used in the study is very high, with a value of $0.05^{\circ}$. The maximum value of the FRD depends on the spatial resolution, in the sense that it increases when the resolution becomes higher.
Table 1. Flash count and flash density in both areas.

\begin{tabular}{lrrrr}
\hline & & & \multicolumn{2}{c}{$\begin{array}{c}\text { Maximum } \\
\text { FRD }\end{array}$} \\
& \multicolumn{2}{c}{ Flash count } & \multicolumn{2}{c}{$\left(\mathrm{fl} \mathrm{yr}^{-1} \mathrm{~km}^{-2}\right)$} \\
\hline & 2012 & 2013 & 2012 & 2013 \\
Area_max & 696144 & 1000687 & 8.6 & 15.3 \\
Area_sec & 526278 & 760405 & 4.4 & 5.9 \\
ratio & 1.32 & 1.32 & 1.94 & 2.59 \\
\hline
\end{tabular}

By comparing with the values reported by Soula et al. (2016) at a resolution of $0.1^{\circ}$, it is clear that the maximum of the annual FRD is larger for $0.05^{\circ}$. Indeed, it is $12.86 \mathrm{fl} \mathrm{km}^{-2} \mathrm{yr}^{-1}$ at $0.1^{\circ}$ and $15.33 \mathrm{f} \mathrm{km}^{-2} \mathrm{yr}^{-1}$ at $0.05^{\circ}$ in 2013 , and it is $8.22 \mathrm{fl} \mathrm{km}^{-2} \mathrm{yr}^{-1}$ at $0.1^{\circ}$ and $8.62 \mathrm{fl} \mathrm{km}^{-2} \mathrm{yr}^{-1}$ at $0.05^{\circ}$ in 2012. On the other hand, the maximum number of stormy days is lower with the resolution of $0.05^{\circ}$, from 189 to 125 days for 2013 and from 167 to 99 days for 2012. This observation is consistent since a day is stormy when at least one flash is detected in the pixel.

The difference between the distributions in the two areas clearly appears regarding both lightning FRD and number of days of the year with lightning activity in Fig. 2. Indeed, the highest values of both parameters are located in the same region of the $5^{\circ} \times 5^{\circ}$ frame for Area_max, while they are much more scattered in the frame for Area_sec. The difference between both areas is stronger for FRD compared to the number of days with thunderstorms, which means that the number of flashes per stormy day is larger for Area_max. This means that the storms in Area_max are more active and/or more stationary, and/or more numerous (Soula et al., 2016). 

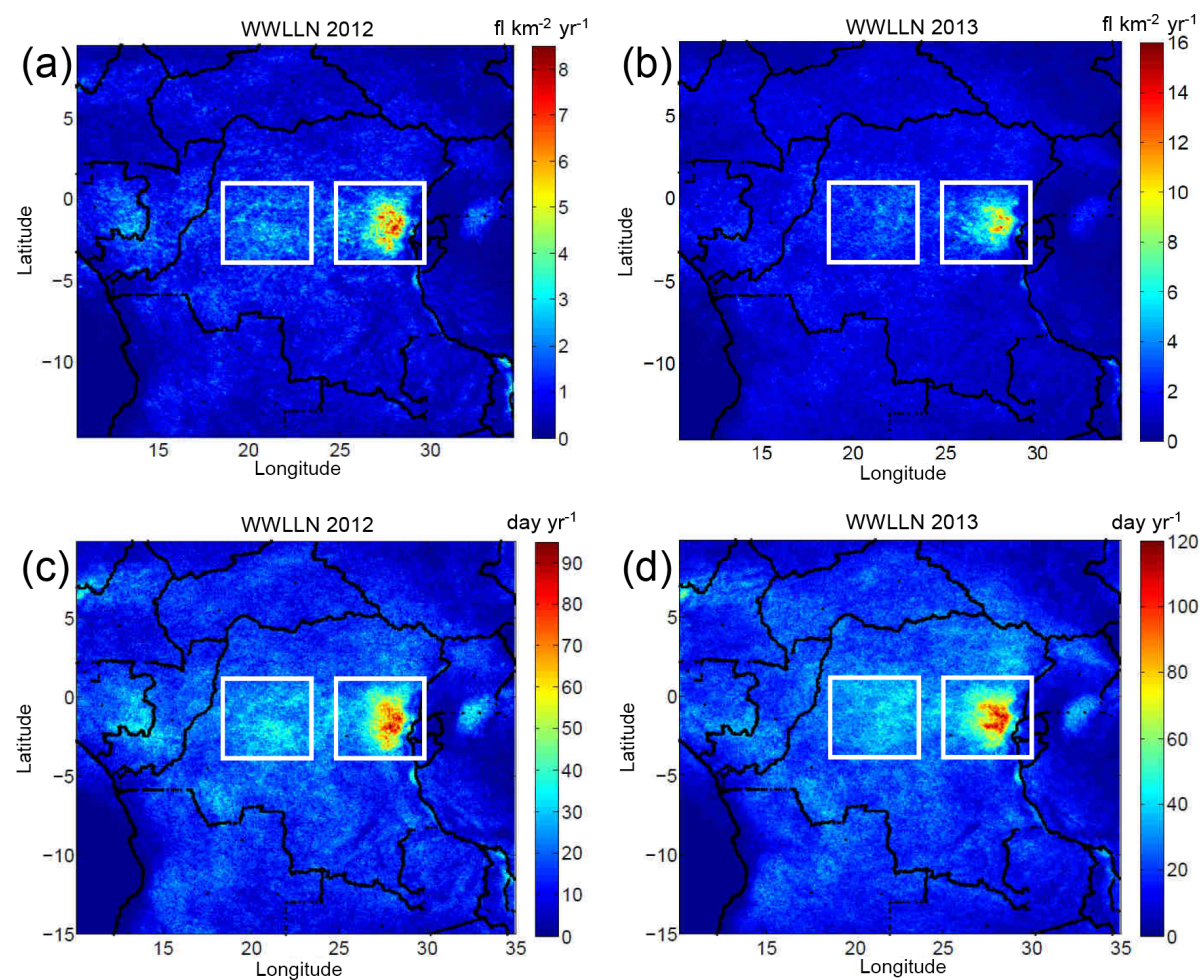

Figure 2. (a, b) Lightning FRD in $\mathrm{fl} \mathrm{km}^{-2} \mathrm{yr}^{-1}$ calculated at a resolution of $0.05^{\circ}$ from WWLLN data in the area of Congo Basin for 2012 and 2013, respectively. (c, d) Number of days of the year with thunderstorm activity in the same area with a resolution of $0.05^{\circ}$ for 2012 and 2013, respectively. The white frames indicate the two zones with strong activity (left, Area_sec; right, Area_max).

The differences observed in the maximum values and the distributions of the lightning FRD indicate specific conditions for the thunderstorm development in Area_max. These conditions are the presence of a mountain range that exceeds $3000 \mathrm{~m}\left(28.75^{\circ} \mathrm{E}, 1.5-2.2^{\circ} \mathrm{S}\right)$, on the west side of which the FRD increases markedly, and the presence of the Lake Kivu $\left(29.2^{\circ} \mathrm{E}, 1.9^{\circ} \mathrm{S}\right)$, above which the FRD increases (Soula et al., 2016). No specific shape of the FRD or stormy day is visible in Area_sec.

\subsection{Daily cycle}

Figure 3 shows the daily cycle of the flashes detected by the WWLLN in Area_max and Area_sec, for 2012 and 2013. The time is indicated in UTC, which is $2 \mathrm{~h}$ late compared to local time $(\mathrm{LT}=\mathrm{UTC}+2)$. These flash counts are calculated over $1 \mathrm{~h}$ and averaged over all days of the year. The timescale of the graph is made so that the flashes are associated with the beginning of the $1 \mathrm{~h}$ period of calculation. Both areas exhibit the same type of diurnal lightning activity with a large proportion of flashes during the afternoon and whatever the year. The minimum and maximum numbers of flashes are observed roughly at the same time in both areas. The minimum is observed in the morning between 08:00 and 09:00 UTC for Area_max and between 07:00 and 08:00 UTC for Area_sec, for both years. The maximum is observed in the afternoon, between 16:00 and 17:00 UTC for Area_max and for both years and for Area_sec in 2013, and between 17:00 and 19:00 UTC for Area_sec in 2012. The contrast in flash counts between the morning minimum and the afternoon maximum is stronger for Area_max (ratio of 14.5 and 15.4, for 2012 and 2013, respectively) than for Area_sec (ratio of 6.2 and 4.7, for 2012 and 2013, respectively). It means the diurnal cycle is much more pronounced in Area_max. Consequently, while the lightning flash rate is larger in Area_max for the main part of the day, it is lower during a short interval between 06:00 and 10:00 UTC corresponding to the minimum activity in both areas.

\subsection{Day-to-day variability}

We compare the lightning activity in both areas in terms of daily distribution of flashes detected during 1 year. The years of reference are 2012 and 2013 with a total of 366 and 362 days, respectively, available in the database. The flash count is performed day by day in each area and then the days are classified by range of flash numbers. Thus, Table 2 displays the result of the classification for each area and each year, over 12 classes of flash number. This result is expressed in terms of number of days for each area and year, and in proportion (\%) of the total number of days for the year in each area. The range of each class is over 1000 flashes, except for 
Table 2. Number of days corresponding to lightning classes in the two study areas during the 2012 (366 days) and 2013 (362 days). The percentage is calculated in relation to the total number of days during the year.

\begin{tabular}{lrrrrrr}
\hline Flash number & CLASS & \multicolumn{3}{c}{ Number of days (\%) } \\
\cline { 7 - 7 } \cline { 6 - 7 } \cline { 6 - 7 } & & \multicolumn{2}{c}{2012} \\
\cline { 7 - 8 } & & Area_max & Area_sec & & Area_max & Area_sec \\
\hline $0-100$ & CL0 & $7(1.91)$ & $59(16.12)$ & & $4(1.10)$ & $43(11.88)$ \\
$101-1000$ & CL1 & $121(33.06)$ & $130(35.52)$ & & $80(22.10)$ & $121(33.43)$ \\
$1001-2000$ & CL2 & $99(27.05)$ & $68(18.58)$ & & $79(21.82)$ & $58(16.02)$ \\
$2001-3000$ & CL3 & $73(19.94)$ & $52(14.21)$ & & $70(19.34)$ & $52(14.36)$ \\
$3001-4000$ & CL4 & $30(8.20)$ & $24(6.56)$ & & $43(11.88)$ & $29(8.01)$ \\
$4001-5000$ & CL5 & $16(4.37)$ & $17(4.64)$ & & $38(10.50)$ & $17(4.70)$ \\
$5001-6000$ & CL6 & $10(2.73)$ & $7(1.91)$ & & $18(4.97)$ & $12(3.31)$ \\
$6001-7000$ & CL7 & $4(1.09)$ & $4(1.09)$ & & $12(3.31)$ & $11(3.04)$ \\
$7001-8000$ & CL8 & $2(0.55)$ & $1(0.27)$ & & $7(1.93)$ & $10(2.76)$ \\
$8001-9000$ & CL9 & $4(1.09)$ & $1(0.27)$ & & $2(0.55)$ & $2(0.55)$ \\
$9001-10000$ & CL10 & $0(0.00)$ & $0(0.00)$ & & $2(0.55)$ & $2(0.55)$ \\
$>10000$ & CL11 & $0(0.00)$ & $0(0.00)$ & & $7(1.93)$ & $5(1.38)$ \\
\hline Total & & $366(100)$ & $366(100)$ & $362(100)$ & $362(100)$ \\
\hline
\end{tabular}
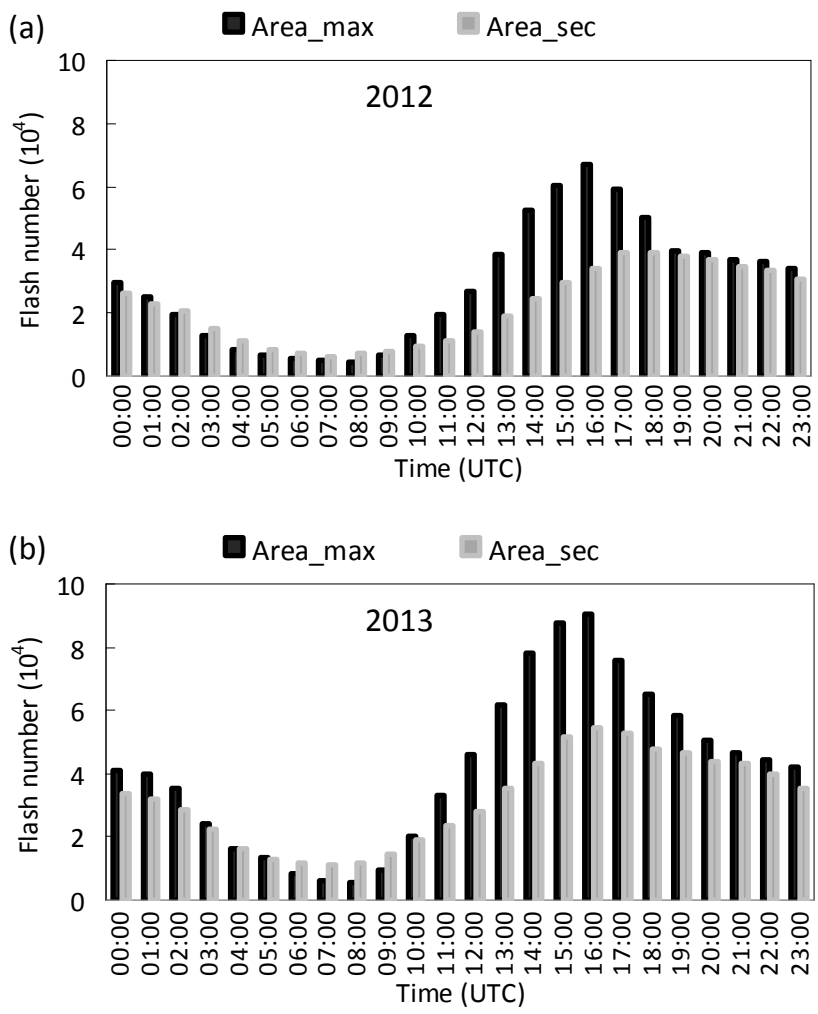

Figure 3. Daily evolution of the hourly lightning flash counts in Area_max and Area_sec for 2012 (a) and 2013 (b).

the first two classes CL0 (0-100 flashes) and CL1 (101-1000 flashes). The first class CL0 corresponds to $0-100$ flashes to distinguish the days with a very low number of flashes. The last class (CL11) groups the days with more than 10000 flashes. To make the interpretation of the results easier, they are also plotted in Fig. 4.

The distribution is similar for both years, (a) for 2012 and (b) for 2013. The number of days in CL0 is much larger for Area_sec than for Area_max (59 and 7, respectively, in 2012, 43 and 4 in 2013), as indicated in Table 2. For CL1, corresponding to the flash numbers 101-1000, the number of days is also larger for Area_sec, with 130 days in 2012 and 121 in 2013, compared to Area_max, which has 121 days in 2012 and 80 days in 2013. On the other hand, the number of days for classes corresponding to intermediate flash numbers (CL2 to CL4 in 2012, CL2 to CL6 in 2013) is significantly larger for Area_max, for both the cumulative number of days (202 compared to 144 in 2012 and 248 compared to 168 in 2013) and for each class considered separately. For the classes with a very high activity (CL5 to CL11 and CL7 to CL11, in 2012 and 2013, respectively) the total number of days is small and not very different in both areas (36 and 30 in 2012, 20 and 30 in 2013, for Area_max and Area_sec, respectively).

From 2012 to 2013, for both areas, the proportion of the number of day decreases in the first three classes (CL0-CL2) and for the cumulative value it is $\sim 62 \%$ in 2012 and $\sim 45 \%$ in 2013 for Area_max, and $\sim 70 \%$ in 2012 and $\sim 61 \%$ in 2013 for Area_sec. It is almost equal in CL3: 20\% in 2012 and $~ 19 \%$ in 2013 for Area_max, and 14\% in 2012 and $\sim 14 \%$ in 2013 for Area_sec. It increases almost in all classes after CL3, and for cumulative value it is $\sim 18 \%$ in 2012 and $~ 36 \%$ in 2013 for Area_max, and 16\% in 2012 and $\sim 25 \%$ in 2013 for Area_sec. 

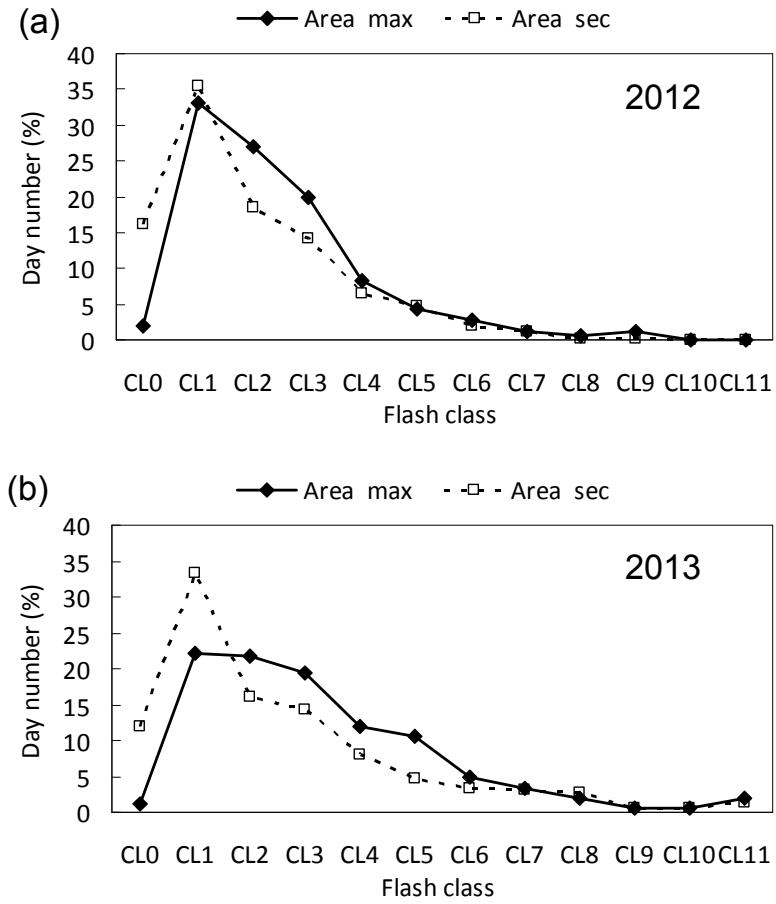

Figure 4. Distribution of the number of days (\% of the annual number of days) versus the classes of flash number in both areas: (a) for 366 days in 2012 and (b) for 362 days in 2013.

\subsection{Correlation between daily lightning activities}

Now we consider the lightning activity for a comparison day by day of both areas to perform a quantitative correlation. The goal is to evaluate whether the storm activities in both areas are simultaneous or shifted in time. In order to illustrate the result about this correlation between lightning activity in Area_max and Area_sec, we display the graph of correlation between the daily lightning flash amounts for both areas and in 2013. These daily counts are calculated in two ways, first by considering the calendar day (00:00-2400 UT) and then according to the daily cycle of lightning activity between two minimums (06:00-06:00 UT; see Fig. 3). Figure 5 shows the result of this correlation study: (a) for the calendar days and (b) for the lightning cycle days.

In the first case the correlation coefficient $R^{2}$ is $\sim 0.118$ and in the second case it is $\sim 0.064$. Thus, the correlation is weak but positive, that is to say, the tendency is that when the daily flash number increases for one area it also increases for the other. At first glance, both distributions are similar. They reflect the trend highlighted by Fig. 4 insofar as the low values ( $\leq 1000$ flashes per day) are more numerous in Area_sec. Inversely, the intermediate values (between 1001 and 5000 flashes per day) are more numerous in Area_max with 230 days in 2013, compared to 156 days for Area_sec. For the values exceeding 10000 flashes per day, there are 7 days for Area_max and 5 days for Area_sec in 2013 (Fig. 5a). In
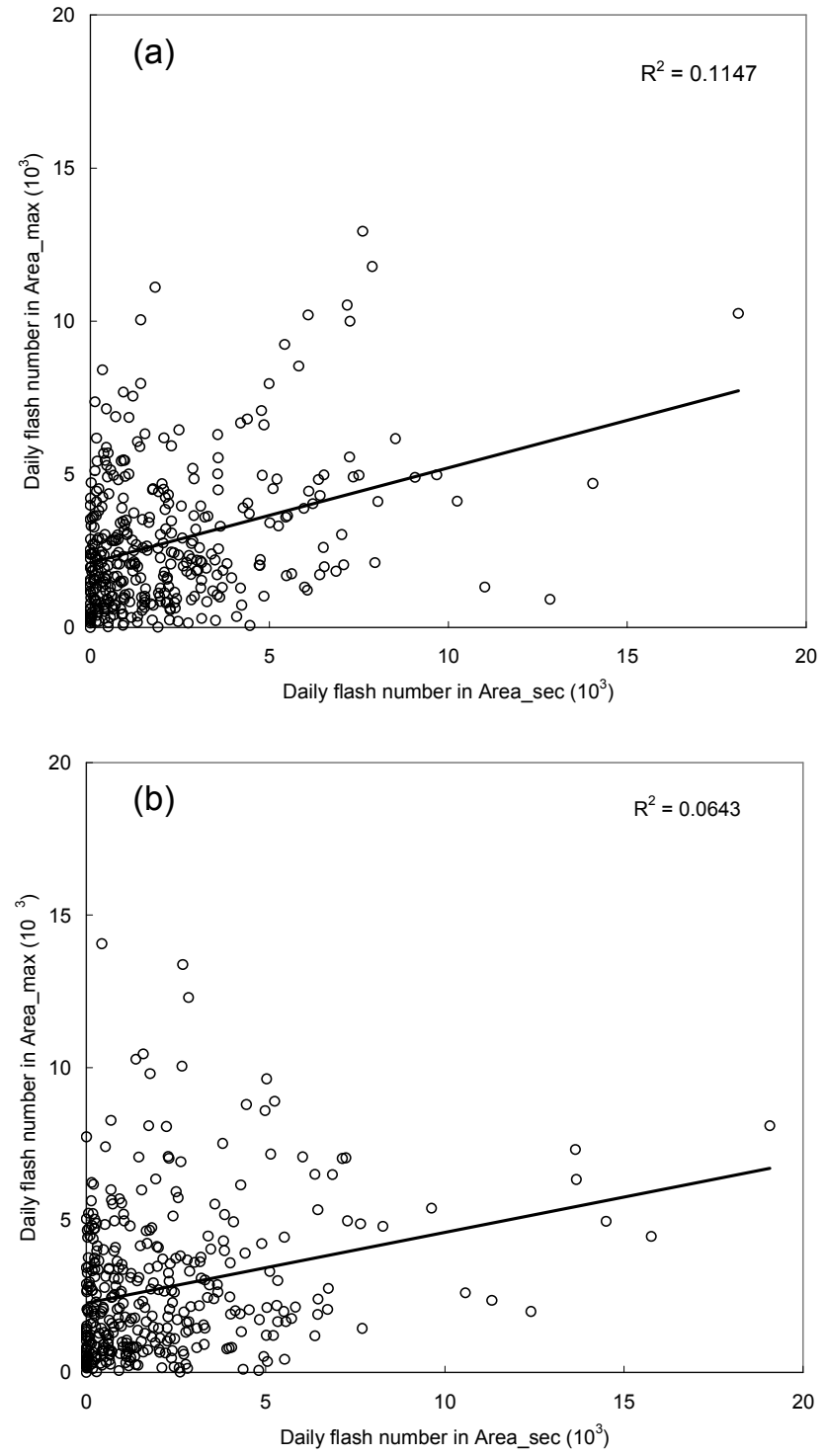

Figure 5. Diagrams of correlation between daily numbers of lightning flashes for Area_max and Area_sec in 2013: (a) at calendar daily scale (00:00-24:00 UTC) and (b) at lightning activity daily scale (06:00-06:00 UTC).

Fig. 5b, these values are 6 and 8, respectively, which means there are more days with a large number of lightning flashes in Area_sec, by considering the daily cycle of the lightning activity. This observation is consistent with the fact that the lightning activity is more widely distributed during the day in Area_sec as indicated in Fig. 3. This may be due to the contribution of nocturnal lightning by mesoscale convective systems (MCSs) or isolated storms that develop later in the afternoon if compared to Area_max. Indeed, the work by Albrecht et al. (2016) shows in their Fig. 3 that during the night, the hotspots located in Area_sec (i.e, 6th and 7th Africa's hotspots) exhibit a larger contribution to the daily lightning activity. Thus, by considering the day according to the light- 

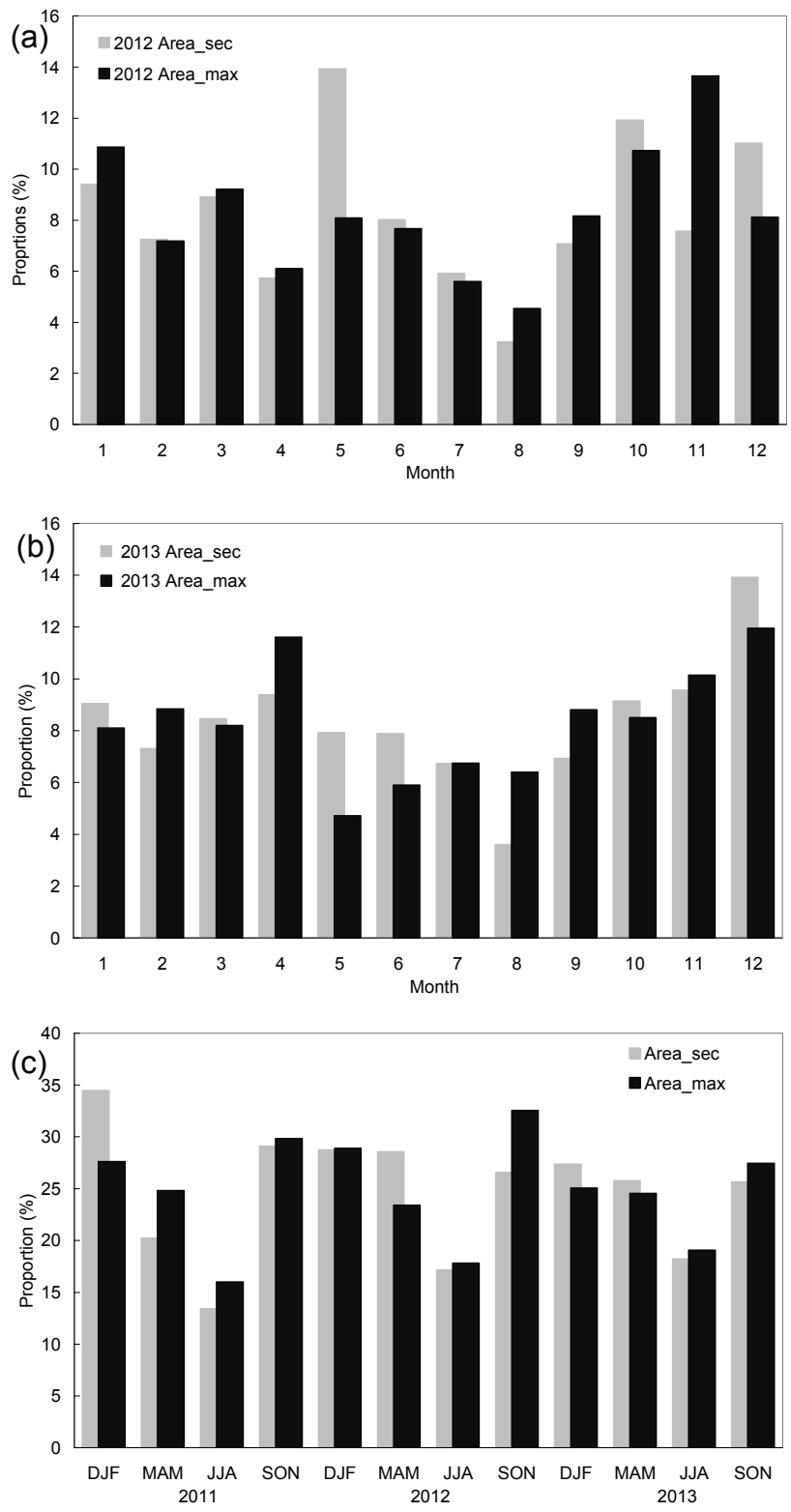

Figure 6. Proportions of flashes detected by WWLLN in Area_max and Area_sec: monthly (a) in 2012 and (b) 2013; (c) seasonally in the period 2011-2013.

ning activity (06:00-06:00), the episodes of strong lightning activity in this area are more likely to be counted in full.

\subsection{Month-to-month variability}

Figure $6 \mathrm{a}-\mathrm{b}$ show the monthly proportion of flashes detected in Area_max and Area_sec during 2012 and 2013. The minimum proportion is found in August and in Area_sec (between 3 and $4 \%$ ) for both years. The maximum proportion is also found in Area_sec in May for 2012 (about 14\%) and in December (about $14 \%$ ) for 2013. These two characteristics show that the variability is always stronger in Area_sec than in Area_max, although the distribution is different from 2012 to 2013 for both areas. For example, in April it is 6.1 and $11.3 \%$ for Area_max, 5.7 and $9.4 \%$ for Area_sec, in 2012 and 2013, respectively. Inversely in May, the proportion of each area is much lower in 2013 compared to 2012 (4.7 and $8.1 \%$ for Area_max, 7.9 and $13.9 \%$ for Area_sec). For a given month, the respective proportions for Area_max and Area_sec remain in the same order, except for the first 3 months of the year.

Figure $6 \mathrm{c}$ shows the 3-month proportion over a longer period including data from 2011 . The 3 -month periods are chosen according to Christian et al. (2003), Jackson et al. (2009), and Soula et al. (2016). Thus, the months of June, July, and August are grouped into JJA; September, October, and November into SON; December, January, and February into DJF; and March, April, and May into MAM. The annual variability at this 3-month scale is more visible and constant from one year to the next. Indeed, for both areas, the minimum is always in JJA with a constant decrease during the preceding 3 -month periods. For the maximum, it seems SON is more favourable to Area_max, while DJF is for Area_sec.

\section{Discussion}

Albrecht et al. (2016) studied the lightning hotspots over the Earth, based on satellite optical observations of lightning. They consider that a hotspot is a region $100 \mathrm{~km}$ in radius around a maximum of FRD. They found that 6 out of the 10 most active spots over the whole African continent, including the three strongest ones, are located in an area corresponding to Area_max, while only two are located in an area corresponding to Area_sec. Our results confirm the predominance of the larger FRD in Area_max.

The characteristics of the diurnal cycle observed in Area_max and Area_sec are consistent with Laing et al. (2011). These authors analysed the cycle of the deep convection over a large area of tropical Africa, including both areas of our study and during 2000-2003. For two $1 \mathrm{~h}$ intervals (14:00-15:00 and 17:00-18:00 UTC) besides eight considered in their study, they found the location of a sharp maximum of the average hourly frequency of coldest clouds in eastern DRC close to Area_max. The intervals 15:00-16:00 and 16:00-17:00 UTC were not plotted in their graphs. They noted this maximum for the two months of April and October analysed in the study. They also showed that the thunderstorm activity is minimum in the part of DRC that corresponds to both areas of our study during the time interval 05:00-06:00 UTC in April and during 08:00-09:00 UTC in October (06:00 and 07:00 UTC were not plotted). The present observations about minimum and maximum lightning activities displayed in Fig. 3 are consistent with those by Laing et al. (2011). Indeed, the maximum of the activity is invariably between 16:00 and 17:00 UTC for Area_max, and in a larger temporal window for Area_sec $(\sim 17: 00$ 

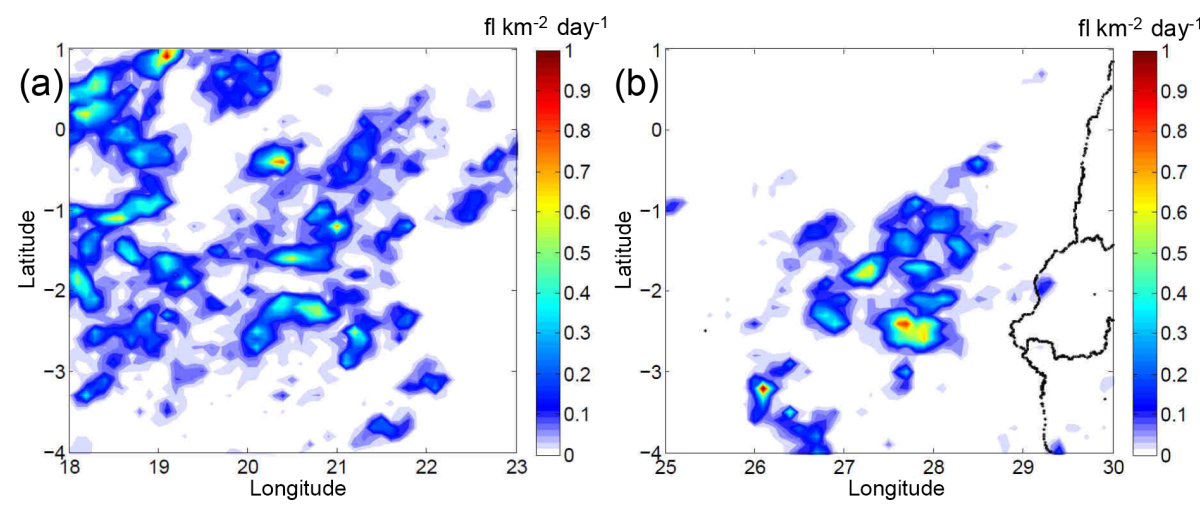

Figure 7. Density of lightning flashes (fl km ${ }^{-2}$ day $^{-1}$ ) detected by WWLLN on 25 December 2013, (a) in Area_sec and (b) in Area_max.

19:00 UTC in 2012 and 16:00-17:00 UTC in 2013). The maximum storm activity is therefore more variable in time for Area_sec. The minimum is invariably between 07:00 and 08:00 UTC for Area_sec, between 08:00 and 09:00 UTC for Area_max. In Albrecht et al. (2016) for the study of lightning hotspots, the daily cycles are considered for several hotspots located in our areas. They found a daily cycle more pronounced for the hotspots included in Area_max compared to the hotspots included in Area_sec, which is consistent with the present study.

The comparison of the monthly activity in Area_max and Area_sec in 2012 and 2013 suggests that the seasonal contrast is stronger in Area_sec, where the maximum monthly amounts are observed in May and December, respectively, and the minimum in August for the 2 years. At the seasonal scale, the lightning activity is cumulated over 3 months following the seasons considered in Soula et al. (2016) for the whole Congo Basin. The inter-annual variability is well visible and reproduced from one year to the next. Even in these 3 years the minimum proportion is always in August and in Area_sec (about 3 to $4 \%$ ). The maximum proportion is also in Area_sec but in different months (from 14 to $16 \%$ ). Therefore, the seasonal contrast is much stronger in Area_sec than in Area_max. This result, due to the migration of the Intertropical Convergence Zone (ITCZ), is consistent with the contrast of the seasonal variation in lightning activity found in Soula et al. (2016). Area_max is less impacted by the migration of the ITCZ because the triggering of thunderstorms in this area has a very local origin.

The positive correlation observed between the daily activities of the two areas means there may be an influence between them or a common cause to explain the storm activity. However, the low value of the correlation coefficient indicates the activities can be different on the quantitative aspect. Figure 7 displays the daily density of lightning flashes detected by WWLLN on 25 December 2013 in Area_sec (a) and in Area_max (b). This day is considered because the activity is strong in both areas with 18107 and 10257 flashes detected in Area_sec and Area_max, respectively. Firstly, this distribution shows the lightning density is high (scale in $\mathrm{fl} \mathrm{km}^{-2} \mathrm{day}^{-1}$ ) in local spots that correspond to convective cores of thunderstorms. In other words, for a given day, the lightning activity can be strong in a restricted area and weak around in terms of flash number. This characteristic of the storm activity is well known and pointed out by many works (Carey et al., 2005; Soula et al., 2014). Secondly, the majority of the lightning spots seem east-west elongated, which could indicate a propagation of the storms within this direction. Thus, the strong activity of a given storm is probably limited over the time. However, the correlation between both areas probably exists because of the eastward propagation of conditions favourable to the development of thunderstorms, as instability of the atmosphere. Indeed, Laing et al. (2011) showed convection over equatorial Africa can be modulated by different conditions at synoptic scale for local occurrence or propagation of MCSs. They especially mentioned the eastward-moving equatorially trapped Kelvin waves, the south-westerly monsoonal flow and the midlevel easterly jets. It is therefore consistent to obtain a low correlation between our two areas characterized by a strong annual storm activity. Furthermore, the correlation study is done at the scale of the day and as most thunderstorms develop at the end of the day, storm activity can occur during the following day in Area_sec, which is several hundred kilometres to the west.

The distribution of storms in the Congo Basin mainly results from four contributions, namely development, propagation, merging, and regeneration of thunderstorms. As thunderstorms can develop everywhere in the Congo Basin, they can naturally form in both Area_max and Area_sec. However, the great lakes and numerous mountains of Rift valley close to Area_max offer most favourable conditions for development and enhancement of thunderstorms. The most intense storms, at planetary scale, are found in the Congo Basin (Zipser et al., 2006). Area_max is probably the most active region in the world in terms of thunderstorms since the number of days of the year with thunderstorm activity is found to be maximum there (Fig. 2c-d) and the density of 
lightning is large over this extended area (Soula et al., 2016). On the other hand, according to previous studies, equatorial Africa thunderstorms spread from the east to the western Congo Basin (Laing et al., 2011; Nguyen and Duvel, 2008; Laing and Fritsch, 1993). Then thunderstorms may propagate from Area_max to Area_sec, but different processes such as merging and regeneration may affect their intensity and induce different characteristics in these areas. Several studies have shown that heterogeneity of soil moisture or vegetation plays a role in the triggering of thunderstorms triggering (Taylor et al., 2011; Garcia-Carreras et al., 2010). Furthermore, the modelling results of the Global Land Atmosphere Coupling Experiment (GLACE) classified equatorial Africa, including Area_max and Area_sec, among the regions of strong coupling between the atmosphere and the soil moisture (Koster et al., 2004). Thus, differences in soil moisture and/or vegetable cover between Area_max and Area_sec may contribute to the differences between lightning activities of the two areas.

Farnsworth et al. (2011) pointed out that the MCSs constitute the fundamental unit of vertical energy transport in Central Africa. In other words, convection in this region generally leads to the formation of MCSs. This observation is consistent with the results of Liu and Zipser (2005) and Zipser et al. (2006) (on deep convection in the Congo Basin). They showed convection in the Congo Basin frequently overshoots the tropopause. The climatology of MCSs in equatorial Africa, including the whole Congo Basin, was presented in Jackson et al. (2009). From a 5-year series of data, these authors have shown that the zone straddling the equator between $5^{\circ} \mathrm{S}$ and $5^{\circ} \mathrm{N}$ and extending from the Atlantic coast to the west side of the high mountains of the Rift Valley is the most active in terms of storms because it includes three maxima of the number of MCSs among the four they identified. In our study, Area_max and Area_sec coincide with the region where Jackson et al. (2009) found the main number maximum of MCS. In Jackson et al. (2009) two cores appeared in the structure of this main maximum: one that corresponds to Area_sec with a less pronounced maximum of number of MCS and a larger number of lightning flashes per MCS, and the second core corresponds to Area_max with a more pronounced maximum. They explain the origin of the large number of MCS in this large area by a maximum of midtropospheric convergence on the west side of the African easterly jet of the Southern Hemisphere (AEJ-S). They observe that this condition is more pronounced in the SON season compared to MAM in the same way that we also observe more flashes according to Fig. 6c. Indeed, according to Mohr and Thorncroft (2006) and Laing et al. (2008), the vertical shear related to the African easterly jet (AEJ) influences the location of intense convective systems. Furthermore, mountain ranges help to initiate long-lived MCSs (Laing et al., 2008, 2011). According to these authors, in all the regions the convection initiates over the elevated terrain and then propagates in conditions of moderate vertical shear to develop into mesoscale systems. On the other hand and according to several authors, the propagation of convection in equatorial Africa is modulated by convectively coupled, equatorial Kelvin waves (Laing et al., 2011). During the active phase of these eastward-propagating large-scale waves, MCSs are larger and more intense. These convective systems occur farther east from day to day and propagate westward within the Kelvin wave envelope. During the dry phase of the Kelvin waves an upper-level convergence is produced, which eliminates the deep convection and the westward propagation. Thus, the region corresponding to Area_max seems to have a stronger maximum of MCS number, as we find a larger FRD. Area_max combines two conditions favourable for thunderstorm activity: the convergence evoked by Jackson et al. (2009) for the large region and a local orographic effect that reinforces the effect of the first one. Area_sec seems to take advantage of the westward propagation/regeneration of MCS, at a distance from the initial occurrence that depends on the phase of the Kelvin waves, which explains the widespread large values of FRD observed within this area.

The presence of mountains or elevated terrain is always a determining factor in the mechanism of thunderstorm. For example, on a very local scale, Munoz et al. (2016) explain the role of the topography combined with nocturnal low-level jet in the largest FRD in the world observed in the region of the Lake Maracaibo, Venezuela. On a more global scale, Williams and Sátori (2004) compared the lightning and rainfall activities in both the Amazon and Congo basins and explained that the larger values of FRD observed in the Congo Basin were due to a more continental environment (drier and warmer) and a higher elevation.

According to Zipser et al. (2006) the proportion of intense convective events is larger in the region corresponding to Area_sec compared to that corresponding to Area_max (see their Fig. 3). This result is consistent with the present Fig. 5 concerning the distribution of the daily flash number in each area, especially the panel (b), where the flash counts are made from 06:00 to 06:00 UTC. Furthermore, the DE is a little lower in Area_sec compared to Area_max, according to the results displayed in Fig. 1. Thus, Area_sec is concerned by more irregular thunderstorm activity, with both the least active days and the most active days. It is well illustrated with the example in Fig. 7, displaying the daily lightning activity for the most active day in Area_sec (see Fig. 5a). Indeed, the FRD for the day is more scattered in the whole area for Area_sec. The distribution of thunderstorm activity is substantially different in each area, concentrated with a very marked daily cycle in Area_max, and scattered with a daily cycle much less pronounced. 


\section{Conclusions}

The spatial and temporal characteristics of the lightning activity are analysed in two areas of the Congo Basin: Area_max with the strongest thunderstorm activity and Area_sec with a secondary maximum. First, the lightning flashes are much more concentrated in the same part of Area_max for both years, while they are widespread in Area_sec. Secondly, the frequency of days with low activity is larger in Area_sec and the frequency of days with high activity is larger in Area_max. However, the frequency of days with very high activity is similar in both areas and even the largest daily flash numbers are detected in Area_sec. Thirdly, a stronger contrast between the maximum and the minimum in the daily cycle is observed in Area_max with a ratio of about 15.4, while it is only 4.7 for Area_sec. In conclusion, the thunderstorm activity is more variable in Area_sec, in terms of location, daytime of occurrence, seasonal distribution, and intensity in terms of number of flashes. These differences are consistent because Area_max combines two favourable effects for thunderstorm development, the convergence associated with the AEJ-S, especially during SON and DJF, and a geographic effect due to the orography and the presence of a lake. The location of the strong convection in Area_sec is widespread, according to the distance and direction of propagation/regeneration of MCSs that initiate farther eastern, especially in relation to the phase of Kelvin waves.

Data availability. All data used in this paper can be requested from the corresponding author, Serge Soula (serge.soula@ aero.obsmip.fr).

Competing interests. The authors declare that they have no conflict of interest.

Acknowledgements. The authors thank the World Wide Lightning Location Network (http://wwlln.net/) and Christelle Barthe from the University of la Réunion (France) for providing the lightning location data used in this study. Jean K. Kigotsi is grateful to the French "Ministère des Affaires Etrangères", to the French Embassy in DRC, especially Patrick Demougin, for supporting his stay in France and "Groupe International de Recherche en Géophysique Europe/Afrique" (GIRGEA), especially Christine Amory, for help with cooperation. Jean K. Kigotsi thanks Albert Kazadi from the University of Kinshasa for his support, help and discussions.

Edited by: Vassiliki Kotroni

Reviewed by: Earle Williams and one anonymous referee

\section{References}

Abarca, S. F., Corbosiero, K. L., and Vollaro, D.: The World Wide Lightning Location Network and convective activity in tropical cyclones, Mon. Weather Rev., 139, 175-191, 2011.

Albrecht, R. I., Goodman, S. J., Petersen, W. A., Buechler, D. E., Bruning, E. C., Blakeslee, R. J., and Christian, H. J.: The 13 years of TRMM Lightning Imaging Sensor: from individual flash characteristics to decadal tendencies, Proceedings of the XIV International Conference on Atmospheric Electricity, 08-12 August 2011, Rio de Janeiro, Brazil, 2011.

Albrecht, R., Goodman, S., Buechler, D., Blakeslee, R., and Christian, H.: Where are the lightning hotspots on Earth?, B. Am. Meteorol. Soc., 97, 2051-2068, https://doi.org/10.1175/bams-d-1400193.1, 2016.

Carey, L. D., Murphy, M. J., McCormick, T. L., and Demetriades, N. W. S.: Lightning location relative to storm structure in a leading-line, trailing-stratiform mesoscale convective system, J. Geophys. Res., 110, D03105, https://doi.org/10.1029/2003JD004371, 2005.

Cecil, D., Buechler, D. E., and Blakeslee, R. J.: Gridded lightning climatology from TRMM-LIS and OTD: Dataset description, Atmos. Res., 135, 404-414, https://doi.org/10.1016/j.atmosres.2012.06.028, 2014.

Christian, H. J., Blakeslee, R. J., Boccippio, D. J., Boeck, W. L., Buechler, D. E., Driscoll, K. T., Goodman, S. J., Hall, J. M., Koshak, W. J., Mach, D. M., and Stewart, M. F.: Global frequency and distribution of lightning as observed from space by the Optical Transient Detector, J. Geophys. Res., 108, 4005, https://doi.org/10.1029/2002JD002347, 2003.

Dowden, R. L., Brundell, J. B., and Rodger, C. J.: VLF lightning location by time of group arrival (TOGA) at multiple sites, J. Atmos. Solar-Terr. Phys., 64, 817-830, 2002.

Farnsworth, A., White, E., Williams, C. J., Black, E., and Kniveton, D. R.: Understanding the Large Scale Driving Mechanisms of Rainfall Variability over Central Africa, in: African Climate and Climate Change, edited by: Williams, C. and Kniveton, D., Advances in Global Change Research, Vol. 43, Springer, Dordrecht, https://doi.org/10.1007/978-90-481-3842-5_5, 2011.

Garcia-Carreras, L., Parker, D. J., Taylor, C. M., Reeves, C. E., and Murphy, J. G.: Impact of mesoscale vegetation heterogeneities on the dynamical and thermodynamic properties of the planetary boundary layer, J. Geophys. Res., 115, D03102, https://doi.org/10.1029/2009JD012811, 2010.

Jackson, B., Nicholson, S. E., and Klotter, D.: Mesoscale convective systems over western equatorial Africa and their relationship to large-scale circulation, Mon. Weather Rev., 137, 1272-1294, https://doi.org/10.1175/2008MWR2525.1, 2009.

Koster, R. D., Dirmeyer, P. A., Guo, Z., Bonan, G., Chan, E., Cox, Peter, Gordon, C. T., Kanae, S., Kowalczyk, E., Lawrence, D., Liu, P., Lu, C., Malyshev, S., McAvaney, B., Mitchell, K., Mocko, D., Oki, T., Oleson, K., Pitman, A., Sud, Y. C., Taylor, C. M., Verseghy, D., Vasic, R., Xue, Y., and Yamada, T.: Regions of strong coupling between soil moisture and precipitation, Science, 305, 1138-1140, https://doi.org/10.1126/science.1100217, 2004.

Laing, A. G. and Fritsch, J. M.: Mesoscale convective complexes in Africa, Mon. Weather Rev., 121, 2254-2263, 1993. 
Laing, A. G., Carbone, R. E., Levizzani, V., and Tuttle, J. D.: The propagation and diurnal cycles of deep convection in northern tropical Africa, Q. J. Roy. Meteor. Soc., 134, 93-109, 2008.

Laing, A. G., Carbone, R. E., and Levizzani, V.: Cycles and propagation of deep convection over equatorial Africa, Mon. Weather Rev., 129, 2832-2853, 2011.

Liu, C. and Zipser, E. J.: Global distribution of convection penetrating the tropical tropopause, J. Geophys. Res., 110, D23104, https://doi.org/10.1029/2005JD006063, 2005.

Mohr, K. I. and Thorncroft, C. D.: Intense convective systems in West Africa and their relationship to the African easterly jet, Q. J. Roy. Meteor. Soc., 132, 163-176, 2006.

Munoz, A. G., Daz-Lobaton, J., Chourio, X., and Stock, M. J.: Seasonal prediction of lightning activity in north western Venezuela: Large-scale versus local drivers, Atmos. Res., 172, 147-162, https://doi.org/10.1016/j.atmosres.2015.12.018, 2016.

Nguyen, H. and Duvel, J. P.: Synoptic wave perturbations and convective systems over equatorial Africa, J. Climate, 21, 63726388, 2008.

Rodger, C. J., Brundell, J. B., Holzworth, R. H., and Lay, E. H.: Growing Detection Efficiency of the World Wide Lightning Location Network, Am. Inst. Phys. Conf. Proc., Coupling of thunderstorms and lightning discharges to near-Earth space: Proceedings of the Workshop, Corte (France), 23-27 June 2008, 1118, 15-20, https://doi.org/10.1063/1.3137706, 2008.
Rodger, C. J., Brundell, J. B., Hutchins M., and Holzworth, R. H.: The world wide lightning location network (WWLLN): Update of status and applications, 29th URSI General Assembly and Scientific Symposium (URSI GASS), Beijing (P. R. of China), 1623 August, 2014.

Soula, S., Iacovella, F., van der Velde, O., Montanyà, J., Füllekrug, M., Farges, T., Bór, J., Georgis, J.-F., NaitAmor, S., and Martin, J.-M.: Multi-instrumental analysis of large sprite events and their producing storm in southern France, Atmos. Res., 135, 415-431, https://doi.org/10.1016/j.atmosres.2012.10.004, 2014.

Soula, S., Kigotsi, K. J., Georgis, J. F., and Barthe, C.: Lightning climatology in the Congo Basin, Atmos. Res., 178-179, 304319, https://doi.org/10.1016/j.atmosres.2016.04.006, 2016.

Taylor, C. M., Gounou, A., Guichard, F., Harris, P. P., Ellis, R. J., Couvreux, F., and De Kauwe, M.: Satellite detection of soil moisture impacts on convection at the mesoscale, Geophys. Res. Lett., 33, L03404, https://doi.org/10.1029/2005GL025252, 2011.

Williams, E. R. and Sátori, G.: Lightning, thermodynamic and hydrological comparison of the two tropical continental chimneys, J. Atmos. Sol.-Terr. Phys., 66, 1213-1231, 2004.

Zipser, E. J., Cecil, D. J., Liu, C., Nesbitt, S. W., and Yorty, D. P.: Where are the most intense thunderstorms on Earth, B. Am Meteorol. Soc., 1057-1071, https://doi.org/10.1175/BAMS-878-1057, 2006. 